\title{
Os perigos da curiosidade: uma leitura de "Cachinhos Dourados e os Três Ursos" de Roald Dahl
}

The danger of curiosity: an interpretation of

"Goldilocks and The Three Bears" by Roald Dahl

\section{$\underline{\underline{\text { Valquiria Pereira Alcantara }}}$}

1 Mestre e doutoranda em Letras pela Universidade de São Paulo. Professora de língua inglesa na Faculdade de Tecnologia de São Paulo. valquiria.alcantara@fatec.sp.gov.br 
RESUMO: Ao longo do tempo, inúmeras versões de contos de fadas foram e continuam sendo publicadas e em nosso trabalho propomos um estudo comparativo da versão dahliana de "Cachinhos Dourados e os Três Ursos" em língua inglesa com a tradução para a língua portuguesa publicada no Brasil. Nosso objetivo é observar como ambos os textos verbais dialogam com as ilustrações de Quentin Blake, pois partimos do pressuposto de que o efeito cômico está ancorado na interação entre o texto verbal e as ilustrações. Em nossa análise observamos, principalmente, as funções e relações que se estabelecem entre os textos verbal e visual descritas pela pesquisadora Sophie Van der Linden, que se dedica ao estudo do livro ilustrado, bem como os estudos de Zohar Shavit a respeito da tradução de literatura infantil. Como resultado buscamos uma melhor compreensão da articulação que se estabelece entre o texto verbal e o visual uma vez que a presença da ilustração é de suma importância no âmbito da literatura infantil.

PALAVRAS-CHAVE: Conto de fadas; Literatura infantil; Tradução de literatura infantil; Roald Dahl; Quentin Blake.

ABSTRACT: Over the years, many different versions of fairy tales have been and still are published. In our paper we present a comparative study of Dahl's version of "Goldilocks and the Three Bears" and the translation into Portuguese published in Brazil. We aim to observe the interaction between both texts and the illustrations by Quentin Blake as we believe the comic effect is grounded by the interaction amongst both verbal texts and the illustrations. In our analysis we consider mainly the relations and functions established between verbal and visual texts according to Sophie Van der Linden and we also look at some specificities of the translation of literature for children considering Zohar Shavit's point of view. As a result, we intend to reach a better understanding of the articulation of both verbal and visual texts as the presence of illustrations in books for children is highly important.

KEYWORDS: Fairy tales; Literature for Children; Translation of Literature for Children; Roald Dahl; Quentin Blake. 


\section{Introdução}

A leitura de contos de fadas encanta adultos e crianças inseridas em diversas culturas há muito tempo. $\mathrm{O}$ encantamento despertado pelos contos tradicionais também estimula inúmeras releituras que podem ser direcionadas a diferentes públicos dentre as quais destacamos as versões parodísticas. Roald Dahl é um consagrado autor britânico que escreveu para adultos e crianças, dentre suas obras destacamos Revolting Rhymes, uma obra que inclui a releitura de seis contos de fadas, a saber: "Cinderela", "Branca de Neve e os sete anões", "João e o pé de feijão", "Cachinhos Dourados", "Chapeuzinho Vermelho e o lobo" e "Os três porquinhos". O presente trabalho tem como objeto de análise o conto "Cachinhos Dourados" de Roald Dahl e referimo-nos à outras edições sempre que pertinente.

Para o desenvolvimento da análise do conto, partimos do pressuposto de que a interação dos textos verbal e imagético fundamentam o efeito de humor presente na obra. A proposta de análise de Sophie Van der Linden, principalmente sua leitura da relação existente entre o texto verbal e ilustrações, nos serve de fundamentação pelo fato de representar uma proposta de análise abrangente e pertinente para o desenvolvimento de nosso trabalho. Também buscamos em Zohar Shavit uma fundamentação teórica adequada para a reflexão acerca de nosso objeto de estudo porque Dahl constrói sua versão do conto de forma a dialogar simultaneamente com leitores adultos e infantis em um texto ambivalente encerrando camadas de significados relevantes. Apresentamos sucintamente as relações e funções que se estabelecem entre texto verbal e texto visual assim como observações de Shavit a respeito da ambivalência no texto para crianças e, em seguida, nossas observações sobre o texto dahliano.

\section{Sophie Van der Linden: o diálogo entre texto verbal e imagético}

No capítulo "Aspectos linguísticos da tradução", Jakobson identifica três possibilidades de tradução: 
1). A tradução intralingual ou reformulação (rewording) consiste na interpretação dos signos verbais por meio de outros signos da mesma língua.

2). A tradução interlingual ou tradução propriamente dita consiste na interpretação dos signos verbais por meio de alguma outra língua.

3). A tradução inter-semiótica ou transmutação consiste na interpretação dos signos verbais por meio de sistemas de signos não-verbais (JAKOBSON, pp. 64/65, s/d).

Embora o autor não tenha se detido na terceira categoria tanto quanto nas duas primeiras, interessa-nos particularmente a terceira categoria. A possibilidade apontada por Jakobson de que o verbal possa ser traduzido por um sistema não verbal leva-nos a refletir como essa interação pode ser estabelecida e que efeitos podem emergir dessa interação. Lund (2012), no artigo “A 'história da cegonha', de Karen Blixen, e a noção de ilustração" discute o que chama de "ilustração antifônica" (LUND, 2012, p. 180) a partir de três exemplos

\footnotetext{
Na maioria dos casos de interação entre o texto verbal e a ilustração, a imagem faz o papel de escrava. Entretanto, em City of Glass, A Sentimental fourney e The Rose and the Ring, as figuras se emancipam. Os livros apresentam diálogos entre palavras e imagens que desempenham papéis iguais. É semelhante ao que os musicólogos denominam de "antífona" ou "canção antifônica”, em que dois coros interagem e cantam alternando frases musicais. Nesse texto, na falta de melhor termo, chamo esta espécie de representação visual de "ilustração antifônica” (LUND, 2012, p. 180).
}

Depreendemos do texto acima que a relação estabelecida entre texto verbal e visual ultrapassa a possibilidade de mera repetição e que o diálogo entre ambos os textos pode ser muito rico. Lund (2012) afirma ainda que "As ilustrações em narrativas literárias sempre são feitas depois que o texto está terminado. Ao contrário, ilustrações antifônicas são incorporadas ao texto logo no início. Elas ou são feitas por um artista instruído pelo autor ou pelo próprio autor." (LUND, 2012, p. 181). Quando o próprio autor ilustra seus trabalhos, pensamos ser natural que durante o processo de criação as ilustrações possam ser produzidas segundo as necessidades do próprio processo criativo, ou seja, o desenvolvimento do projeto pode determinar se o texto verbal e o texto visual serão desenvolvidos paralelamente, por exemplo. Por 
outro lado, pensamos que o trabalho do ilustrador feito a partir do texto verbal concluído também possa guardar um grau de antifonia, pois o ilustrador é um leitor que interage com o texto verbal e colabora para a construção de sentido por meio das imagens que produz. Assim, entendemos que as relações e funções descritas por Linden (2011) em Para ler o livro ilustrado, principalmente a relação de disjunção e as funções de contraponto e amplificação sejam, de fato, a leitura de ilustrações antifônicas a partir de outra perspectiva.

Sophie Van der Linden (2011) apresenta não só uma discussão acerca da definição de livro ilustrado, mas também apresenta aspectos relevantes para a análise de livros ilustrados. Interessa-nos, particularmente, sua discussão sobre as relações observáveis entre texto verbal e texto visual considerando aspectos estéticos, plásticos e gráficos. Em sua análise, Linden (2011) apresenta três possíveis relações que se estabelecem entre texto verbal e visual e seis funções. Para compreendermos as relações e funções presentes, é necessário observar que, segundo a autora, uma linguagem assume primazia em relação a outra, ou seja, quando se inicia a experiência de leitura, o texto verbal ou o texto imagético vai atrair a atenção do leitor constituindo, de acordo com a nomenclatura da autora, a "instância primária" (LINDEN, 2011, p. 122). Ainda segundo a autora, essa "primazia" na leitura está intimamente relacionada com aspectos gráficos como a diagramação, posição do texto e da imagem no espaço da página, a ocupação ou não da página dupla, para citar alguns elementos. Considerando a possibilidade de tradução intersemiótica apontada por Jakobson , entendemos que a primazia de leitura a qual se refere Linden (2011) permite as duas vias de tradução, ou seja, o texto verbal pode traduzir o texto visual da mesma forma que o visual pode traduzir o texto verbal. Isso ocorre, a nosso ver, porque ambos os textos interagem de maneira dinâmica, se a leitura teve início com a imagem em uma primeira interação, ao final do processo, o leitor pode sentir a necessidade de retomar a leitura interagindo com o texto verbal antes do visual.

Linden (2011) vê na relação de redundância a possibilidade de ambos os textos, verbal e imagético remeterem o leitor para a mesma narrativa, não havendo, portanto, acréscimo de informação. Nesse caso pode haver a sobreposição total, quando a imagem repete o texto verbal ou sobreposição parcial, quando a imagem repete parcialmente o texto verbal; na relação de colaboração ambos os textos contribuem para a construção do sentido da narrativa e 
esta não se completa quando há ausência de um ou outro texto. A terceira relação identificada por Linden é a de disjunção, quando texto verbal e imagens contam histórias paralelas ou, até mesmo contraditórias permitindo ao leitor diferentes interpretações.

Considerando a função que a instância secundária pode assumir em relação à instância primária, Linden (2011) observou as seguintes possibilidades: repetição quando a instância secundária repete "a mensagem veiculada pela instância prioritária.” (LINDEN, 2011, p. 123); de seleção quando a instância secundária repete parcialmente a instância primária; de revelação quando a instância secundária fornece informações, às vezes detalhes, da instância primária dando sentido a esta e a interação de ambas possibilita a construção do sentido; na função completiva a instância secundária completa lacunas ou explicita informações que ficaram subentendidas na instância primária, dessa forma a instância secundária interfere na instância primária e é possível a construção de sentido; na função de contraponto é comum a quebra de expectativas, pois o texto verbal pode trazer aspectos da narrativa que a ilustração pode, inclusive, contradizê-los. Quando isso acontece, a tendência do leitor é tomar a imagem como verdadeira, ou por outra, tendemos a creditar na mensagem veiculada pelo texto imagético e não pelo verbal. A última função descrita é a de amplificação, quando um texto diz mais que o outro, até mesmo sugerindo interpretações. Nesse caso, um texto não contradiz ou repete o outro, mas apresenta mais informações e permite ao leitor diferentes leituras.

Essa breve apresentação das relações e funções descritas por Linden (2011) nos possibilita a proposta de leitura da versão dahliana de "Cachinhos Dourados" que apresentamos adiante, porém cabe ainda mais alguns comentários acerca de aspectos teóricos que fundamentam nossa leitura. Comentaremos, a seguir, alguns aspectos relativos à tradução de literatura infantil na perspectiva de Zohar Shavit.

\section{Ambivalência de um texto literário: breves observações}

Zohar Shavit (2009), em Poetics of Children's Literature, observa importantes aspectos da literatura infantil e da tradução desta. Interessa-nos especificamente a discussão proposta pela autora sobre a ambivalência do texto para crianças. Um autor de textos para crianças depara-se 
constantemente com a possibilidade de produzir um texto que, tendo a criança como público alvo, pode desagradar o leitor adulto e é, em geral, considerado não canônico; em oposição a esta situação, há autores que usam o leitor infantil como pretexto e produzem obras que, de fato, tem o leitor adulto como alvo e têm suas obras consideradas em consonância com o cânone. Sabe-se que o posicionamento de um texto no polissistema literário pode variar de acordo com a dinâmica do próprio sistema e modelos que eram considerados canônicos no sistema literário para adultos, quando começam a ser rejeitados dentro desse sistema, podem ser incorporados no sistema literário infantil quando são manipulados de maneira a receber aceitação nesse outro sistema.

Com efeito, temos que modelos pertencentes ao sistema para adultos, muitas vezes repetidos a exaustão, ao longo do tempo deixam de ser considerados adequados e são rejeitados nesse sistema. No entanto, ainda não podem ser considerados adequados para serem incorporados ao sistema literário infantil e, para tanto, são manipulados de maneira a atender convenções próprias do sistema infantil. Para ser considerada adequada para o leitor infantil, a obra deve, do ponto de vista do adulto, ter complexidade adequada à possibilidade de compreensão da criança, deve tratar temas sensíveis como a morte, por exemplo, de modo a não ferir a sensibilidade da criança; aspectos estilísticos e ideológicos também devem ser considerados adequados para a criança e os recursos linguísticos idealmente devem contribuir para o enriquecimento linguístico do leitor infantil. Viagens de Gulliver é um exemplo desse tipo de mudança de posicionamento dentro do sistema literário, pois inicialmente era um texto próprio do sistema literário adulto e depois de simplificações, seleções e adequações de aspectos linguísticos, foi incorporado ao sistema literário infantil. Esse tipo de mudança de paradigma, obviamente, não exclui o adulto como leitor de obras como essa.

É possível, segundo Shavit (2009), compreender um texto como ambivalente quando do ponto de vista do sistema literário adulto, o texto apresenta um nível de sofisticação que, $a$ priori, seria considerado inadequado para o leitor infantil, contudo, por se tratar de um texto que manipula modelos existentes, permite ao leitor infantil a apreciação do texto ainda que não seja capaz de apreender algumas camadas de sentido acessíveis ao adulto. Como resultado da manipulação de modelos existentes, obras consideradas ambivalentes usualmente têm a 
criança como público alvo oficial e um público alvo real que não é necessariamente a criança. A ambivalência a que se refere Shavit (2009) está intimamente ligada à relação assimétrica entre adultos e crianças no que tange a literatura para os leitores infantis, pois trata-se de uma produção feita por adultos e, via de regra, analisada e avaliada por adultos (familiares ou professores, por exemplo) antes de que efetivamente chegue às mãos dos pequenos leitores. Essa intermediação está filtrada pela forma como a infância é vista pelo autor e pelo grupo social no qual tanto o autor quanto aqueles que avaliarão e disponibilizarão a obra para as crianças se inserem. Dessa relação assimétrica resulta que a literatura infantil pode ser compreendida como uma obra de arte com qualidades estéticas e que propõe o questionamento e busca da compreensão do mundo, mas também como veículo pedagógico cujo principal objetivo é "ensinar" algo às crianças. Apresentamos, a seguir, nossa análise de "Cachinhos Dourados" de Roald Dahl à luz do ponto de vista de Zohar Shavit a respeito da possível ambivalência de um texto e das relações que se estabelecem entre texto verbal e visual segundo a classificação de Sophie Van der Linden.

\section{"A história dos três ursos": observações iniciais}

Antes de iniciarmos nossa análise propriamente dita, apresentamos algumas informações preliminares a respeito do conto tradicional. Segundo notas de Joseph Jacobs acerca da origem do conto,

\footnotetext{
"Os três ursos" é o único exemplo que conheço de um conto cuja autoria pode ser identificada e que tenha se tornado um conto popular. Além disso o conto desenvolveu-se de forma curiosa e instrutiva com a substituição da garotinha de cachinhos dourados por uma velha rude. Na versão de Southey não há nenhuma garota como heroína: aparentemente a personagem foi introduzida em uma versão metrificada de G. N., bastante elogiada por Southey (JACOBS, 1968, p. 300, tradução nossa).
}

Ainda segundo Jacobs (1968), “A história dos três ursos” é um conto publicado em The Doctor, \& c c. que foi apreciado e publicado em várias versões. Considerando as ilustrações 
às quais tivemos acesso e nos referimos a seguir, percebemos que os três ursos poderiam ser três irmãos - possibilidade que reflete o texto verbal - porém a interpretação consagrada é de uma família. Na versão dahliana temos a garota de cachos dourados e a família de ursos.

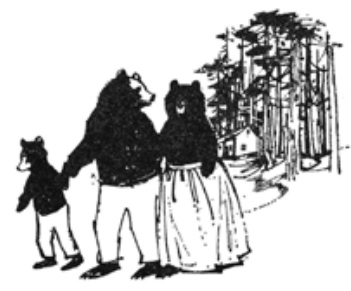

18. The Story of the Three Bears

Figura I - English Fairy Tales, 1968, p. 60

Considerando as observações de Sophie Van der Linden a respeito das relações estabelecidas entre texto verbal e visual, observamos que na edição de 1968 da coletânea English Fairy Tales de Joseph Jacobs e ilustrações de Margery Gill, em "A História dos Três Ursos” houve a inclusão de cabeção no qual vê-se a cena dos três ursos afastando-se da casa para uma caminhada. Chama-nos a atenção o fato de a ilustração apresentar uma família de ursos cujo sexo de cada personagem está identificado por meio da vestimenta dos animais antropomorfizados: o grande urso e o pequeno urso usam calça comprida, enquanto o médio é apresentado como uma fêmea por estar vestindo uma saia. O pequeno urso está segurando a mão direita do urso adulto e este, por sua vez, parece ter o braço esquerdo entrelaçado com o braço direito da ursa. Esta ilustração, segundo a classificação de Linden, assume a função de contraponto em relação ao texto verbal, pois enquanto na ilustração vemos claramente que o urso de tamanho médio é uma fêmea, no texto verbal trata-se de um urso macho uma vez que os pronomes usados para se referir a este personagem são masculinos. 


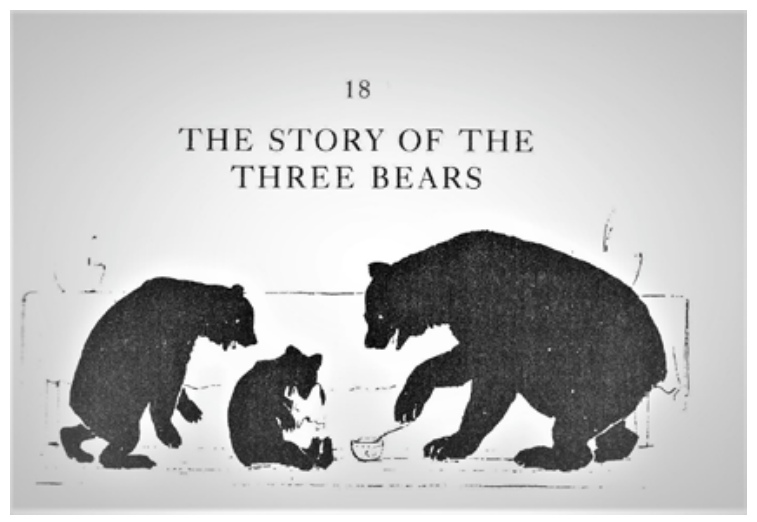

Figure 2 - English Fairy Tales, 1993, p. 97

No entanto, na edição de 1993 há uma ilustração de John D. Batten - também na função de cabeção - na qual vemos três ursos ambiguamente antropomorfizados, pois estão em um ambiente que depreendemos que seja uma sala de jantar onde se vê uma mesa posta coberta com uma toalha e duas tigelas sobre ela, mas os animais não são apresentados com nenhuma vestimenta e o gestual ainda nos faz lembrar que são ursos: os dois animais maiores estão apoiados nas patas traseiras, mas curvados para frente de maneira que uma pessoa não estaria; embora não seja possível identificar se são de fato figuras masculinas, tendemos a identificá-las desta forma. O texto verbal é o mesmo em ambas as edições, porém a relação que se estabelece com a ilustração de Batten é de redundância com sobreposição parcial, pois vemos os ursos em casa e o pequeno urso chora porque sua tigela está vazia. Assim como Batten, em uma coletânea de traduções de contos tradicionais organizada por Ana Maria Machado e publicada em 2010, vemos que Arthur Rackham também havia ilustrado a história em 1933 com a figura de três ursos cujo sexo não é possível identificar; Walter Crane, em 1873, e R. André (s.d.) também ilustraram versões da história assumindo que os três ursos são membros de uma família - pai, mãe e filho. 


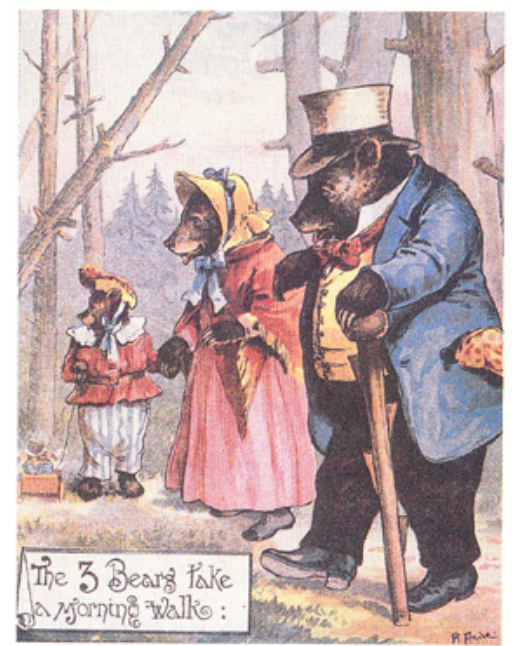

R. André, s/d

Figura 3 - Contos de Fadas, 2010, p. 274.

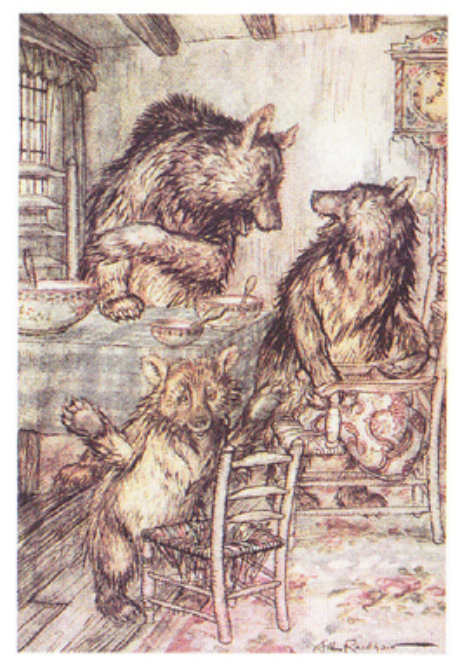

Arthur Rackham, 1933

Figura 4 - Contos de Fadas, 2010, p. 277. 


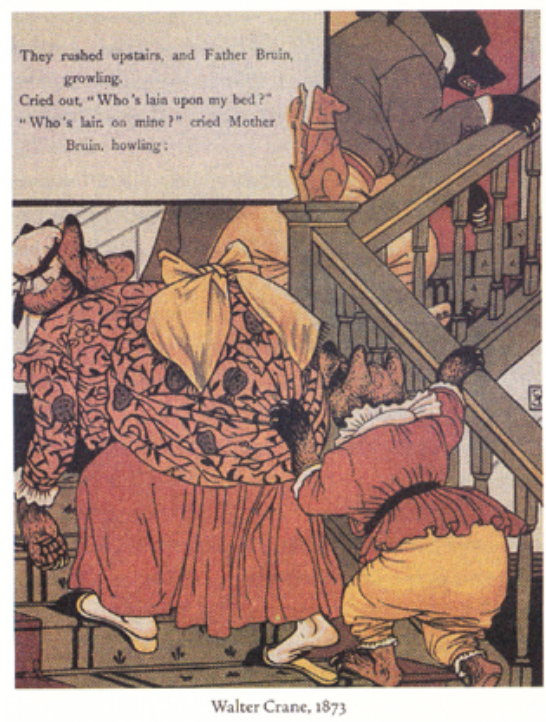

Figura 5 - Contos de Fadas, 2010, p. 276.

Lembramos que ao esclarecer a função de contraponto Linden (2011) afirma: "Mas a segunda instância pode simplesmente dizer o contrário. Nesse caso, cabe observar que, de acordo com minhas investigações, é sempre a imagem que parece falar 'a verdade'.” (LINDEN, 2011, p. 125). Pensamos que tal afirmação parece ser comprovada com as ilustrações de Margery Gill na edição de 1968, Walter Crane em 1873 e R. André (s.d.) pois apesar de o texto verbal deixar claro que há três ursos do sexo masculino, tendemos a ignorar tal informação e assumir as ilustrações como referência. Entendemos que tal leitura está sustentada no fato de os animais serem antropomorfizados, pois têm uma casa para morar com mobiliário adequado ao tamanho de cada um deles e têm o hábito de tomar café da manhã como muitas pessoas o fazem. Essa antropomorfização gera associações com experiências que temos do mundo e, nesse caso em particular, a representação dos ursos como um casal de ursos adultos mais um urso filhote leva, inevitavelmente, à associação com o núcleo familiar. 


\section{O texto dahliano e as ilustrações de Quentin Blake}

Voltando nossa atenção ao texto de Roald Dahl, passaremos a analisar como texto verbal e ilustrações dialogam tendo em conta as opções de diagramação. Na primeira página de "Goldilocks and the Three Bears" há uma vinheta de Quentin Blake na qual observa-se "papai” urso vestido formalmente com uma colher na mão. Nesse caso, segundo a classificação proposta por Linden (2011), a ilustração apresenta-se em relação de redundância com o texto verbal, pois o texto incluído na página termina com a exclamação do urso sobre quão quente está o mingau. Na medida em que não há acréscimo de informação, pode-se dizer que a vinheta assume a função de repetição do texto verbal. Na página seguinte há outra vinheta na qual vemos Goldilocks comendo mingau; nesse caso também há repetição redundante considerando a interação instaurada entre ilustração e texto verbal uma vez que este último nos informa sobre a ação da garota.

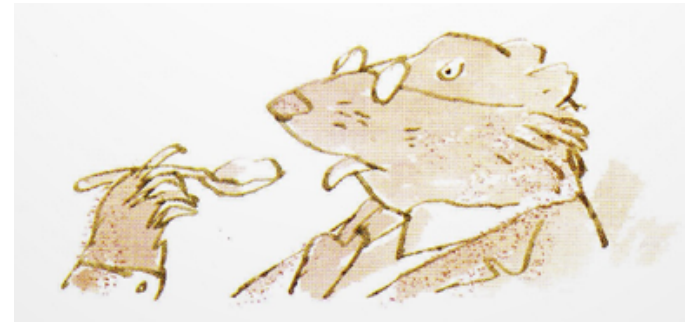

Figura 6 - Revolting Rhymes, 2001, p. 29.

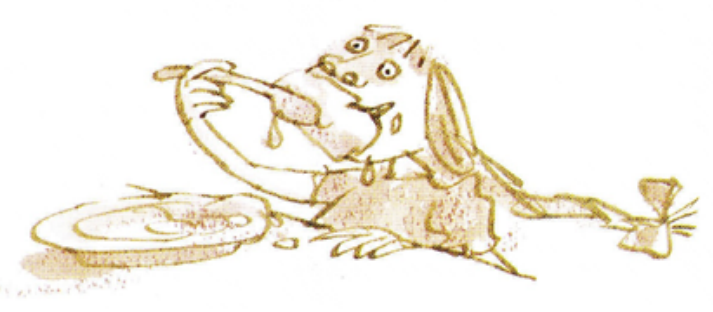

Figurea 7 - Revolting Rhymes, 2001, p. 30.

Cabe, contudo, ressaltar que ainda que ambas as vinhetas retratem dois personagens em ações muito semelhantes, há um claro contraste em relação à atitude de ambos. O urso 
demonstra uma atitude comedida, pois tem uma colher na mão com uma pequena porção de alimento. Por outro lado, a menina, é retratada comendo com sofreguidão, pois parece colocar uma grande quantidade de alimento em sua boca e há, também, respingos que revelam sua falta de modos à mesa. A atitude da menina na ilustração repete o texto verbal na medida em que ela é descrita como uma criança intrometida e de má índole. Não é possível dizer se a menina está vestida com traje formal ou não, enquanto o urso usa terno e gravata, vestimenta que está comumente associada à formalidade e, muitas vezes, à elegância. Esse contraste torna-se mais evidente se levarmos em conta que as atitudes à mesa estão invertidas, pois espera-se que uma pessoa tenha bons modos e associamos a voracidade aos animais. Percebe-se, nesse caso, que as vinhetas repetem o texto verbal quando observadas individualmente, todavia, há contraponto quando são observadas uma em relação à outra.

Na terceira página, há uma ilustração que toma toda a página e mostra a garota entrando na casa dos ursos. Referindo-se aos tipos de diagramação, Linden afirma:

[...] O livro ilustrado herdou do livro com ilustração tradicional a alternância entre página de texto e página com imagens.

Nesse tipo de organização, a imagem costuma ocupar aquilo que os tipógrafos chamam de "página nobre", a da direita - aquela em que o olhar se detém na abertura do livro -, ao passo que o texto fica na página da esquerda (LINDEN, 2011, p. 68). 


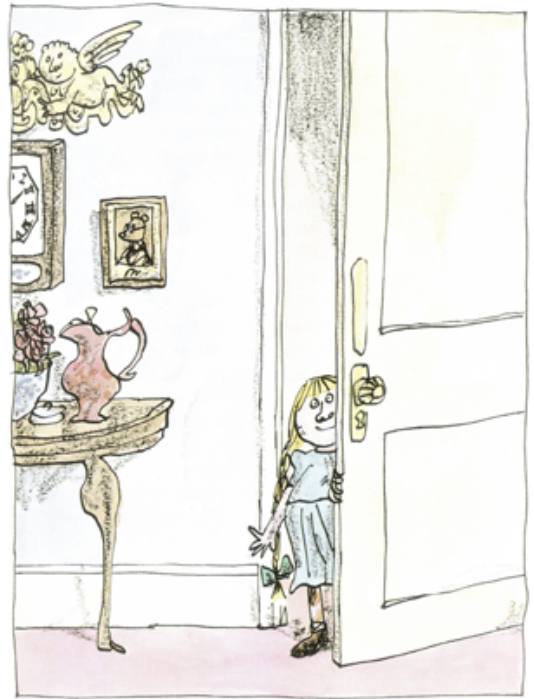

Figura 8 - Revolting Rhymes, 2001, p. 31.

Na obra de Dahl vemos que essa diagramação tradicional foi adotada, ambas as ilustrações maiores foram posicionadas na página da direita e serão comentadas. A primeira grande ilustração traz uma divisão clara que se dá por meio do batente esquerdo da porta de entrada da casa dos ursos: do lado esquerdo vemos alguns detalhes da decoração da casa, retrato do "pai" urso na parede ao lado de um relógio; acima do relógio há a figura parcial de um querubim dourado; abaixo do relógio há um aparador com pé torneado e, sobre o aparador, há um jarro - que poderia ser de louça - e um vaso com flores. Na página seguinte lemos a descrição da decoração da casa e somos informados a respeito do requinte da dona da casa, pois há referência ao estilo Chippendale de mobília que, segundo a Enciclopédia Britânica onli$n e$, foi popular a partir do século 18, teve algumas variações de estilo e foi o primeiro design de mobília designado a partir do nome do profissional que desenvolveu o estilo e não de um monarca como ainda era comum na época; nesse caso, essa porção da ilustração antecipa, por meio de seleção, informações que contribuem para a formação da opinião do leitor quanto à família de ursos. No lado direito da ilustração, observamos a imagem da garota entrando na casa, informação que repete o texto verbal, mas que parece incongruente em relação à vinheta, pois o leitor já sabe que a garota "invadiu" a casa porque a vê comendo o mingau.

Pensamos que a incongruência é apenas aparente na medida em que no texto verbal o narrador refere-se à menina como uma criança "bisbilhoteira", "desprezível" e "ladra" que 
se esgueira na casa vazia. Desse modo, a vinheta que repete seletivamente o texto verbal antecipa a descrição da personagem que nos é revelada surgindo pela porta entreaberta na ilustração da página seguinte. É importante ressaltar, também, que a menina está posicionada, diagonalmente, em oposição ao querubim; enquanto a figura angelical segundo Chevalier e Gheerbrant (1992) está associada a um guardião de templo e nos remete à elevação, à iluminação, ao sublime e ao conhecimento, a menina é descrita de forma negativa com adjetivos que invocam a vileza e o terreno. Ademais, a moldura da ilustração corta a porta da casa não permitindo ver seu topo, mas entendemos que a porta é muito alta porque a menina tem sua cabeça na altura da maçaneta sugerindo a proporção de altura da menina em relação à porta. A nosso ver, a descrição negativa da criança associada à decoração da casa dos ursos e o contraste entre a altura da porta e da menina sugerem, metaforicamente, a inferioridade de caráter da personagem em relação aos ursos que, não só são antropomorfizados, mas também têm características positivas associadas a eles - bons modos e bom gosto no que se refere à decoração da casa e vestimenta (formalidade do "pai” urso).

Quanto à segunda grande ilustração, assim como a primeira, toma uma página inteira e foi posicionada na página da direita após o encerramento do texto verbal. Pode-se ler nos últimos versos:

\author{
'Oh daddy!' cried the Baby Bear, \\ 'My porridge gone! It isn't fair!' \\ 'Then go upstairs,' the Big Bear said, \\ 'Your porridge is upon the bed. \\ 'But as it's inside mademoiselle, \\ 'You'll have to eat her up as well" (DAHL, 2001, p. 34).
}




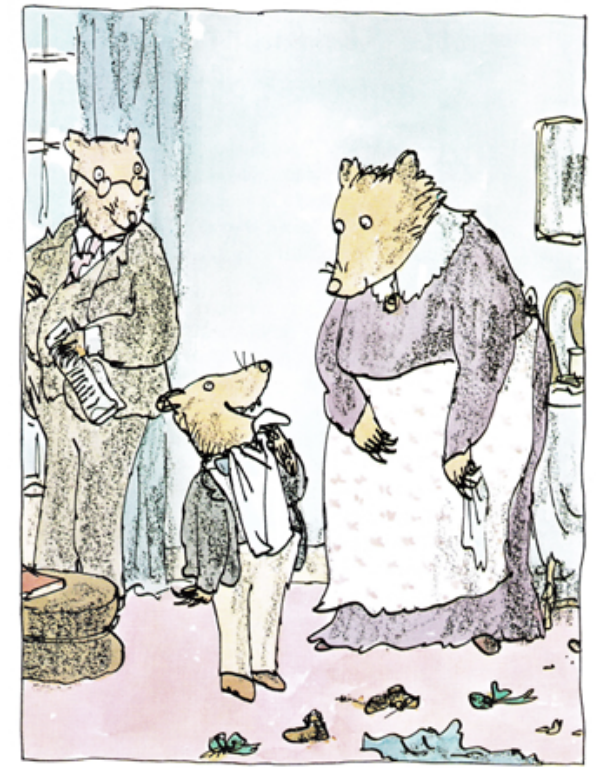

Figura 9 - Revolting Rhymes, 2001, p. 35.

Levando em conta que o último período do texto está estruturado como uma condicional, entendemos que a ação deve acontecer no futuro e compreendemos que o "pai" urso sugere ao pequeno urso o que fazer para finalmente comer seu mingau. A ilustração de Blake nos revela, então, não só que o pequeno urso seguiu o conselho do "pai”, mas também que nada restou da menina, pois vemos seu vestido, seus sapatos e laços jogados pelo chão da sala. Segundo a definição de Linden (2011), a ilustração está em relação de disjunção em relação ao texto verbal, pois amplifica o sentido do texto mostrando ao leitor que ser devorada pelo pequeno urso foi seu castigo por ter agido de maneira reprovável como demonstra o narrador desde o início do conto. Notamos, ainda que ambos "papai” e "mamãe" urso olham para o pequeno urso esboçando um sorriso. O olhar do leitor é atraído para e concentrado no pequeno urso pelo fato de este se encontrar entre os ursos adultos que, por sua vez, olham para baixo em direção ao urso filhote. Na medida em que os animais são apresentados antropomorfizados ao leitor, pode-se inferir que o sorriso esboçado revela aprovação e satisfação. Satisfação porque o pequeno urso acaba de devorar a menina e, portanto, não tem mais fome. Aprovação porque além de ver o pequeno urso alimentado, ele também revela ter aprendido bons modos ao usar o guardanapo adequadamente. Vemos, portanto, que as atitudes dos animais mimetizam o comportamento humano, pois as crianças costumam ser cuidadas por seus pais e elas 
são ensinadas como se comportar nas diversas situações sociais. Nesta cena reforça-se para o leitor a informação dada anteriormente no texto verbal sobre a boa educação e elegância da família de ursos evidenciada pelo terno e gravata usados tanto pelo "pai” urso quanto pelo filhote e pela demonstração de boa educação do pequeno urso.

\section{Luciano Vieira Machado e Quentin Blake: outro diálogo}

No volume traduzido para o português por Luciano Vieira Machado as ilustrações de Quentin Blake foram mantidas, mas cabe comentar o novo diálogo que se estabelece. A ilustração na qual se vê Cachinhos Dourados entrando na casa dos ursos também ocupa toda a página da direita como na edição inglesa, no entanto, ao interagir com o título do conto na página da esquerda, assume a função de revelação ao antecipar ao leitor a ação da personagem. Precedendo o texto verbal, a ilustração não dá indicações acerca do comportamento reprovável da menina - entrar na casa sem convite -, mas invoca o conhecimento prévio do leitor familiarizado com o conto tradicional. Apesar das mesmas informações visuais, o contraste entre a figura da menina e do querubim - parte da decoração da casa - não reproduz o impacto causado no leitor da edição inglesa porque o leitor de língua portuguesa ainda não está informado sobre o caráter da personagem.

As vinhetas presentes na edição inglesa não são as mesmas incluídas na edição brasileira; a primeira vinheta, um conjunto de três pratos, acompanha o texto verbal no momento do enredo em que a menina já comeu o mingau, já se sentou nas cadeiras e está no quarto dos ursos assim como no conto tradicional. A ilustração em si nada revela sobre o comportamento ou caráter da menina diferentemente da vinheta na qual vemos a menina devorando o mingau mostrando sua falta de educação. Quanto à ilustração que mostra a cena do pequeno urso na sala, limpando a boca após devorar a menina, está posicionada na página da esquerda antecedendo o trecho final do texto verbal. Essa opção de diagramação possibilita à ilustração relacionar-se, de acordo com Linden (2011), colaborativamente completando o sentido do texto verbal porque informa ao leitor qual o castigo dado à menina; devido ao posicionamento da ilustração na página da esquerda temos que, nesse ponto da narrativa, o texto verbal passa 
a ter primazia em relação à imagem ao atrair primeiro o olhar do leitor.

A última ilustração que acompanha o texto é uma vinheta que retrata três crianças posicionadas em fila indiana, todas sorrindo e com os braços erguidos. Este gestual sugere que as crianças da vinheta estão comemorando algo e, por estar posicionada depois do final do conto, cabe perguntar o que as crianças da vinheta estariam celebrando. A vinheta pode ser diretamente relacionada ao seguinte trecho do texto: "Mas no livro, vocês verão,/ a malvada escapa sem um arranhão,/ e o coro das crianças em toda parte diz:/ 'Viva! Viva! Viva! Que final feliz!/ A pobre menina conseguiu se safar/ e graças ao bom Deus voltou pro seu lar!”” (DAHL, 2007, p. 41), nesse caso, repetindo parcialmente o texto verbal. Por outro lado, entendemos que o posicionamento da vinheta logo após o encerramento do texto verbal também contribui para uma leitura amplificada, pois desde o início do texto sabemos que Cachinhos Dourados comportou-se de forma reprovável; portanto, é possível compreendermos que a comemoração das crianças também tenha relação com o fato de a menina ter sido castigada no final do conto como consequência dos "crimes" cometidos por ela.

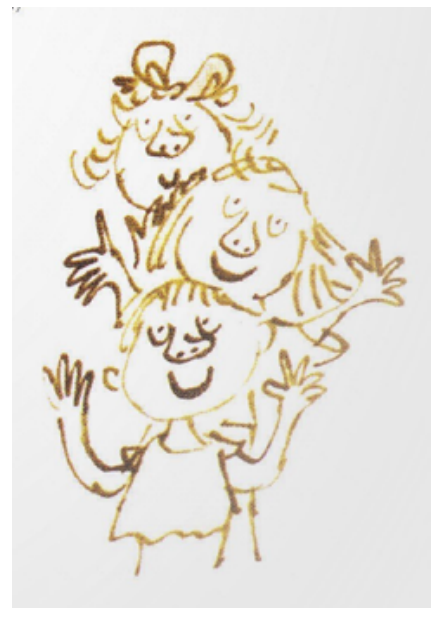

Figura Io - Historinhas em versos perversos, 2007, p. 41.

\section{Ambivalência no texto dahliano}

Retomando o ponto de vista de Shavit (2009) sobre a ambivalência do texto, identificamos a manipulação de dois gêneros que não apresentam características comuns, a saber, o 
conto de fadas e o julgamento de um crime. Esse diálogo improvável é possível porque ambos crianças e adultos reconhecem o conto tradicional e, mais provavelmente o leitor adulto pode reconhecer o julgamento criminal, embora as crianças possam também ser capazes de reconhecer o gênero caso já tenham visto algo semelhante em desenhos animados ou filmes, por exemplo.

No conto tradicional, após as peripécias da menina bisbilhoteira - ou velha em algumas edições - temos o seguinte desfecho:

Ergueu-se num sobressalto. E quando viu os três ursos de um lado da cama, pulou fora pelo outro e correu para a janela. Ora, a janela estava aberta, porque os ursos, como ursos bons e asseados que eram, sempre abriam a janela do quarto ao se levantar de manhã. Cachinhos Dourados pulou da janela; e saiu correndo o mais rápido que podia - sem nunca olhar para trás. E o que aconteceu depois eu não sei dizer, mas os três ursos nunca mais tiveram notícia dela (MACHADO, 2010, p. 280).

$\mathrm{Na}$ versão dahliana, temos um narrador onisciente que assume o papel de contador de histórias, apresenta sua reprovação do conto logo no início da narrativa²:

This famous wicked little tale

Should never have been put on sale.

It is a mystery to me

Why loving parents cannot see

That this is actually a book

About a brazen little crook.

(DAHL, 2001, p. 29)

Essa história famosa é balela, ninguém deve dar crédito a ela.

Eu por mim nunca vou entender por que uma mãe amorosa não vê que a heroína é perversa e atrevida

2 As citações apresentadas lado a lado visam facilitar a visualização para o leitor. 
(Pode haver coisa mais descabida?)

(DAHL, 2007, p. 36).

O conto é desqualificado por meio do uso do adjetivo "wicked" usado para descrever algo ou alguém moralmente reprovável e que pode exercer influência negativa. Além disso, descreve pejorativamente a personagem como uma criminosa cínica usando "brazen" e "crook". Observando a tradução, notamos que o conto é igualmente desqualificado, porém com diferente intensidade, pois optou-se pelo uso de "balela" que corresponde a mentira. O campo semântico de "brazen" pôde ser retomado pelo uso de "perversa" para caracterizar a menina, curiosamente denominada "heroína" no texto em português que, pensamos, remete o leitor aos contos tradicionais nos quais a presença de um herói ou uma heroína é uma constante.

A continuação do texto instaura a disposição condenatória do narrador:

Had I the chance I wouldn't fail

To clap young Goldilocks in jail.

Now just imagine how you'd feel

(DAHL, 2001, p. 29).

Se tivesse a chance, sem dó,

eu a mandaria para o xilindró.

Imagine o que você sentiria

(DAHL, 2007, p. 36).

O uso de itálico em "you'd feel" é um recurso usado por Dahl nesse e em outros textos que reproduz graficamente aspectos da oralidade como mudança de tom de voz, por exemplo. Dado que o narrador declara que Cachinhos Dourados deveria ser presa, pensamos que o narrador assume, então, o tom que um advogado de acusação usaria durante um julgamento. Adiante no texto lemos:

That nosey thieving little louse,

Comes sneaking in your empty house. 


\author{
$[\ldots]$ \\ I say again, how would you feel \\ If you had made this lovely meal \\ And some delinquent little tot \\ Broke in and gobbled up the lot? \\ (DAHL, 2001, p. 30)
}

\begin{abstract}
Mal você põe o pé na estrada
lá vem Cachinhos - menina mimada,

enxerida, ranheta, ladrona, esperta -

e invade a casa deserta.

$[\ldots]$

Eu repito: o que você sentiria

se fizesse uma tal iguaria

e uma pirralha sem fé, sem moral,

devorasse todo o seu mingau?
\end{abstract}

(DAHL, 2007, p 37).

No trecho citado vemos que "nosey thieving" e "louse" também caracterizam pejorativamente a menina e no texto em português há uma transposição por desdobramento, segundo a descrição de Francis Aubert (2006) das modalidades de tradução, pois os dois adjetivos e o substantivo são desdobrados em cinco adjetivos - "mimada, enxerida, ranheta, ladrona, esperta" - todos informais e de conotação negativa com exceção de "esperta" que, dependendo do contexto, pode ser usado positivamente. As duas formas verbais "sneaking in" que pode ser traduzida por "esgueirando" e "broke in" são condensadas no verbo "invadir" tradução usual para a segunda forma verbal e "delinquent" é desdobrado em "pirralha" e "sem moral"; assim como o desdobramento, a condensação também é uma possibilidade de transposição segundo a descrição de Aubert (2006). Como pode ser observado, o autor usa a mesma estrutura do conto tradicional, largamente conhecido, recupera a caracterização dos personagens apresentando os ursos como uma pacata família que vive em uma casa decorada com certo requinte "You have 
collected lovely things/ Like gilded cherubs wearing wings,/ And furniture by Chippendale/ Bought at some famous auction sale.” (DAHL, 2001, p. 32) e substitui a velha (presente em algumas versões do conto) por uma menina igualmente mal-educada e inconveniente.

Ainda sobre a seleção lexical, ressaltamos o uso de "xilindró", "pôr o pé na estrada", "enxerida", "ladrona" que, embora possam não ser de uso corrente entre as crianças atualmente, são expressões bastante informais que aproximam o texto do leitor infantil tanto na leitura intermediada quanto na leitura autônoma. Essa aproximação é relevante no texto de partida e Luciano Vieira Machado obtém efeito semelhante em língua portuguesa.

Enquanto em várias versões do conto a atitude de Cachinhos Dourados pode ser vista como um reflexo da curiosidade infantil que, em geral, não suscita aplicação de castigo porque o desbravamento do mundo é considerado inerente ao universo infantil, o texto dahliano apresenta inovação. Após a apresentação das aventuras da menina na casa dos ursos, cada demonstração de curiosidade da criança é expressa como um crime e todos os crimes cometidos por Cachinhos Dourados são apresentados de forma resumida como se fosse parte das alegações em um julgamento. Ou seja, o autor não está simplesmente recontando a famosa história, mas sim torna o leitor um espectador de um julgamento:

Oh, what a tale of crime on crime!

Let's check it for a second time.

Crime One, the prosecution's case:

She breaks and enters someone's place.

Crime Two, the prosecution notes:

She steals a bowl of porridge oats.

Crime Three: She breaks a precious chair

Belonging to the Baby Bear.

Crime Four: She smears each spotless sheet

With filthy messes from her feet. 
A judge would say without a blink,

'Ten years hard labour in the clink!'

But in the book, as you will see,

The little beast gets off scot-free,

While tiny children near and far

Shout, 'Goody-good! Hooray! Hurrah!

'Poor darling Goldilocks!' they say,

'Thank goodness that she got away!'

Myself, I think I'd rather send

Young Goldie to a sticky end.

'Oh daddy!' cried the Baby Bear,

'My porridge gone! It isn't fair!'

'Then go upstairs,' the Big Bear said,

'Your porridge is upon the bed.

'But as it's inside mademoiselle,

'You'll have to eat her up as well.'

(DAHL, 2001, p. 34).

Repassemos agora, ainda uma vez, essa história de crimes, que pasmar nos fez.

Crime um: entrar numa casa sem permissão.

Coisa muito grave que não tem perdão.

Crime dois: uma vez instalada na casa alheia, rouba um belo prato de mingau de aveia.

Crime três: ela quebra a mais bela mobília do membro mais novo daquela família. 
Crime quatro: emporcalha o lençol limpinho, que a mãe ursa lavou com tanto carinho.

\author{
Um juiz com certeza nem iria piscar: \\ "Dez anos de cana ela tem de pegar!" \\ Mas no livro, vocês verão, \\ a malvada escapa sem um arranhão, \\ e o coro das crianças em toda parte diz: \\ “Viva! Viva! Viva! Que final feliz! \\ A pobre menina conseguiu se safar \\ e graças ao bom Deus voltou pro seu lar!"
}

De minha parte eu acho que ela devia

Ser bem castigada, como merecia.

"Ah, papai”, o pobre ursinho grita,

"Meu mingau sumiu, que coisa esquisita!"

"Vai então lá em cima,", papai urso exclama,

“Teu mingau está em cima da cama,

mas dentro da menina, então note,

comendo a menina, tu o comes também!"

(DAHL, 2007, pp. 39 e 41).

Com o trecho citado acima ilustramos, por um lado, o entrelaçamento dos gêneros conto de fadas e julgamento e, por outro lado, que esse entrelaçamento associado à informalidade que recorre frequentemente ao uso de vocabulário pejorativo constituem o "gatilho do humor" dahliano, para usarmos a nomenclatura de Rosas (2002), criando o efeito cômico a partir de uma fusão improvável de registros: os contos de fada tendem a ser informais, principalmente nas versões mais recentes e um julgamento que tem normas rígidas e o registro bastante formal e cerimonioso. Na citação acima, vemos também que o autor apresenta as ações da menina como uma sequência de crimes, contrapõe a possível opinião condenatória de 
um juiz à reação de alívio e celebração dos leitores infantis diante da fuga ilesa de Cachinhos Dourados na versão tradicional da história, e apresenta a opinião do narrador/ advogado de acusação: a menina deve ser condenada. Em seguida, testemunhamos o diálogo final entre "papai" urso e o pequeno urso sugerindo que o pequeno deve devorar a menina para finalmente comer seu mingau. Nesse contexto, a fala do pai soa como o pronunciamento da sentença e a ilustração de Blake revela que a sentença foi cumprida, ou seja, Cachinhos Dourados foi acusada, julgada, sentenciada e executada na versão dahliana.

\section{Cachinhos Dourados de Dahl: considerações finais}

$\mathrm{Na}$ análise que apresentamos pudemos verificar que as ilustrações de Quentin Blake dialogam com o texto de Roald Dahl em línguas inglesa e portuguesa ora amplificando, ora complementando, ora repetindo o texto verbal. As diferentes funções assumidas pelas ilustrações em relação ao texto verbal possibilitam a construção de um efeito cômico na versão dahliana que contrasta com a versão tradicional da história, costumeiramente apresentada em tom informal, mas não cômico. Além disso, as ilustrações de Blake revelam momentos do texto tradicional possibilitando ao leitor a rememoração da história. Podemos dizer, então, que ambos Dahl e Blake manipulam o texto tradicional de modo a permitir ao leitor reconhecer aquilo que já conhecem e, simultaneamente, o texto verbal agrega características de outro gênero - o julgamento - que se instala e interage perfeitamente com o texto tradicional. Caracteriza-se, dessa forma, a ambivalência a que se refere Shavit (2009), pois Dahl propõe uma atualização do conto tradicional manipulando os elementos constituintes do conto garantindo o reconhecimento da história por adultos e crianças, por um lado, e inserindo elementos de um gênero dialogando diretamente com os leitores adultos.

Além do efeito cômico resultante, apreciado pelos leitores infantis, percebe-se que da manipulação realizada pelo autor resulta uma crítica à imagem genericamente associada à infância. A curiosidade é sabidamente inerente à criança e na versão dahliana do conto é apresentada como um crime de invasão de domicílio que deve ser punido como qualquer outro crime. A consequência dessa nova leitura é que a inocência infantil é desmitificada e a 
criança é mostrada como um ser humano capaz de atitudes reprováveis como qualquer pessoa, adulta ou não. Nesse caso a execução de Cachinhos Dourados após sua condenação sumária, a princípio poderia ser reprovada, mas é atenuada pelo fato de ter sido devorada pelo pequeno urso, portanto seu igual na condição infantil; além disso, a execução da menina resulta do fato de ela ter sido devorada por um animal, fato que está de acordo com o curso da natureza, afinal ursos são ferozes e a ferocidade é reconhecida por todos. Portanto, a consumação do que de fato é uma pena capital não causa estranheza e, simultaneamente, retoma a estrutura dos contos tradicionais, pois Cachinhos Dourados é penalizada assim como aqueles identificados como antagonistas do herói também o são nos contos de fadas.

É possível argumentar e apontar um caráter pedagógico na versão dahliana de Cachinhos Dourados se entendermos o pequeno urso como uma representação da criança que recebe instruções e orientações da família quanto às regras de comportamento. Nessa perspectiva vemos que o texto de Dahl atende às expectativas de adultos que valorizam e esperam encontrar a função pedagógica em obras produzidas para crianças. Por outro lado, é necessário reconhecer o caráter estético do texto que ultrapassa a característica pedagógica quando critica a visão idealizada de infância apresentando Cachinhos Dourados como um ser humano capaz de atitudes reprováveis.

Sabe-se que o autor de Matilda dialogava com leitores infantis respeitando-os como indivíduos e em várias obras apresenta o adulto que desrespeita e, por vezes, maltrata a criança recebendo uma punição. Na história dos ursos vemos, então, que uma criança está sujeita a punição da mesma forma que um adulto estaria ao proceder de forma condenável. Se, de maneira geral, Dahl estabelece um pacto com o leitor infantil dando voz a seus questionamentos e ponto de vista, como entender a punição de uma criança em sua versão do conto tradicional? Pensamos que a resposta para tal questionamento resida justamente em sua crítica ao conto tradicional, ou seja, desde o início do texto o narrador expressa sua reprovação em relação ao texto tradicional. Dessa forma, ao apresentar a protagonista sendo condenada e executada por seus comportamentos reprováveis, podemos entender que, de fato, qualquer indivíduo é passível de punição, o caráter pedagógico pode ser identificado na apresentação do texto, mas não é um fator que limite a função estética do texto. Ao ampliar esta visão do conto, o leitor tem a oportunidade de observar o mundo ao seu redor e questionar o comportamento humano de forma genérica e pensamos que dessa maneira cumpra sua função enquanto obra da arte. 


\section{Referências}

AUBERT, Francis H. "Em busca das refrações na literatura brasileira traduzida- revendo a ferramenta de análise.” In: NITRINI, Sandra (org.) Revista Literatura e Sociedade. $\mathrm{n}^{\circ}$ 9. São Paulo: Humanitas. 2006, p. 60-69.

CHEVALIER, J. \& GHEERBRANT, A. Dicionário de símbolos: (mitos, sonbos, costumes, gestos, formas, figuras, cores, números). $6^{a}$ ed., colaboração de André Barbault [et al.]; coordenação Carlos Sussekind; tradução: Vera da Costa e Silva... [et al.], Rio de Janeiro: José Olympio, 1992.

Chippendale. Enciclopedia Britannica. Discponível em <https://www.britannica.com/topic/ Chippendale> Acesso em 7 de ab. de 2019.

Contos de Fadas: de Perrault, Grimm, Andersen \& outros. Trad. Maria Luiza X. de A. Borges, Apres. Ana Maria Machado. Rio de Janeiro: Zahar, 2010.

DAHL, Roald. Revolting Rhymes. Illustrated by Quentin Blake. London: Puffin Books, 2001. Historinhas em versos perversos. Ilust. Quentin Blake. Trad. Luciano Vieira Machado. São Paulo: Salamandra/ Moderna, 2007.

English Fairy Tales being the two collections English Fairy Tales \& More English Fairy Tales compiled and annotated by Joseph Jacobs, illustrated by Margery Gill, London: The Bodley Head, 1968.

DINIZ, Thaïs Flores Nogueira e VIEIRA, André Soares (org.). Intermidialidade e estudos interartes: desafios da arte contemporânea. Belo Horizonte: Rona Editora: FALE/UFMG, 2012.

Houaiss. Disponível em <https://houaiss.uol.com.br/pub/apps/www/v3-3/html/index.php\#2>. Acesso em 08 de dez. 2019. 
JACOBS, Joseph. English Fairy Tales. With illustrations by John Batten. London: Everyman's Library, 1993.

JAKOBSON, Roman. Linguística e comunicą̧ão. pref. Izidoro Blikstein; trad. Izidoro Blikstein e José Paulo Paes. São Paulo: Editora Cultrix Ltda, s/d.

LINDEN, Sophie Van der. Para ler o livro ilustrado. trad. Dorothée de Bruchard. São Paulo: Cosac Naify, 2011.

LUND, H. “A 'história da cegonha', de Karen Blixen, e a noção de ilustração”. In: Intermidialidade e estudos interartes: desafios da arte contemporânea, 2012.

ROSAS, Marta. Tradução de humor: transcriando piadas. Rio de Janeiro: Lucerna, 2002.

SHAVIT, Zohar. Poetics of Children's Literature. Athens/ London: University of Georgia Press, 2009 (paperback edition) 